\title{
Geothermometry of hot springs in the Malawi Rift
}

Estefanny Dávalos Elizondo ${ }^{1 *}$, Eliot A. Atekwana ${ }^{2}$, Estella A. Atekwana ${ }^{2}$, Gift Tsokonombwe ${ }^{3}$, and Daniel A. Laó-Dávila ${ }^{1}$ Boone Pickens School of Geology, Oklahoma State University, 105 Noble Research Center, Stillwater, OK 74078, ${ }^{2}$ Department of Geological Sciences, 101 Penny Hall, University of Delaware, Newark, DE 19716 ,

ABSTRACT

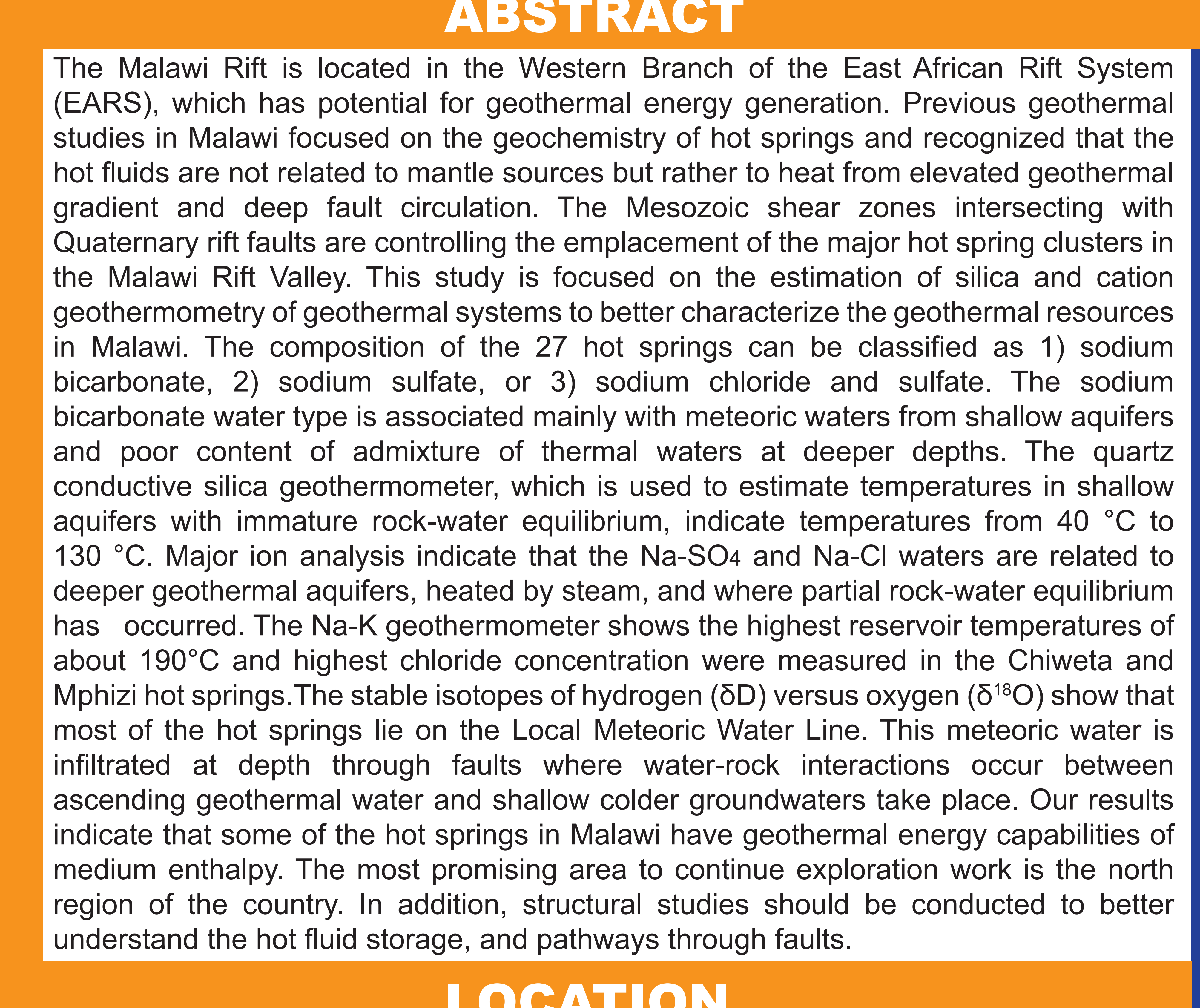$$
\text { LOGATION }
$$



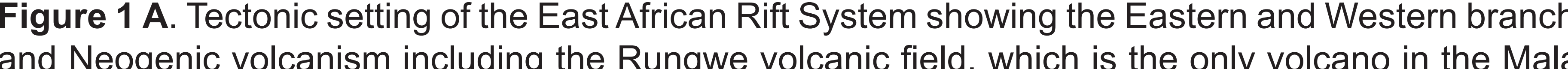

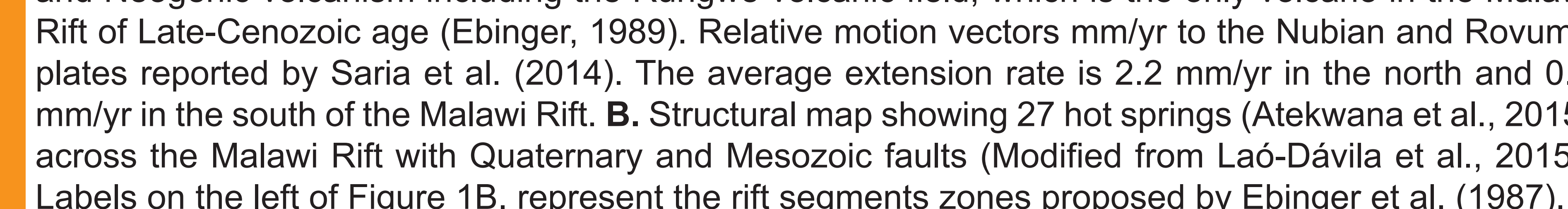

\section{MOTIVATION}

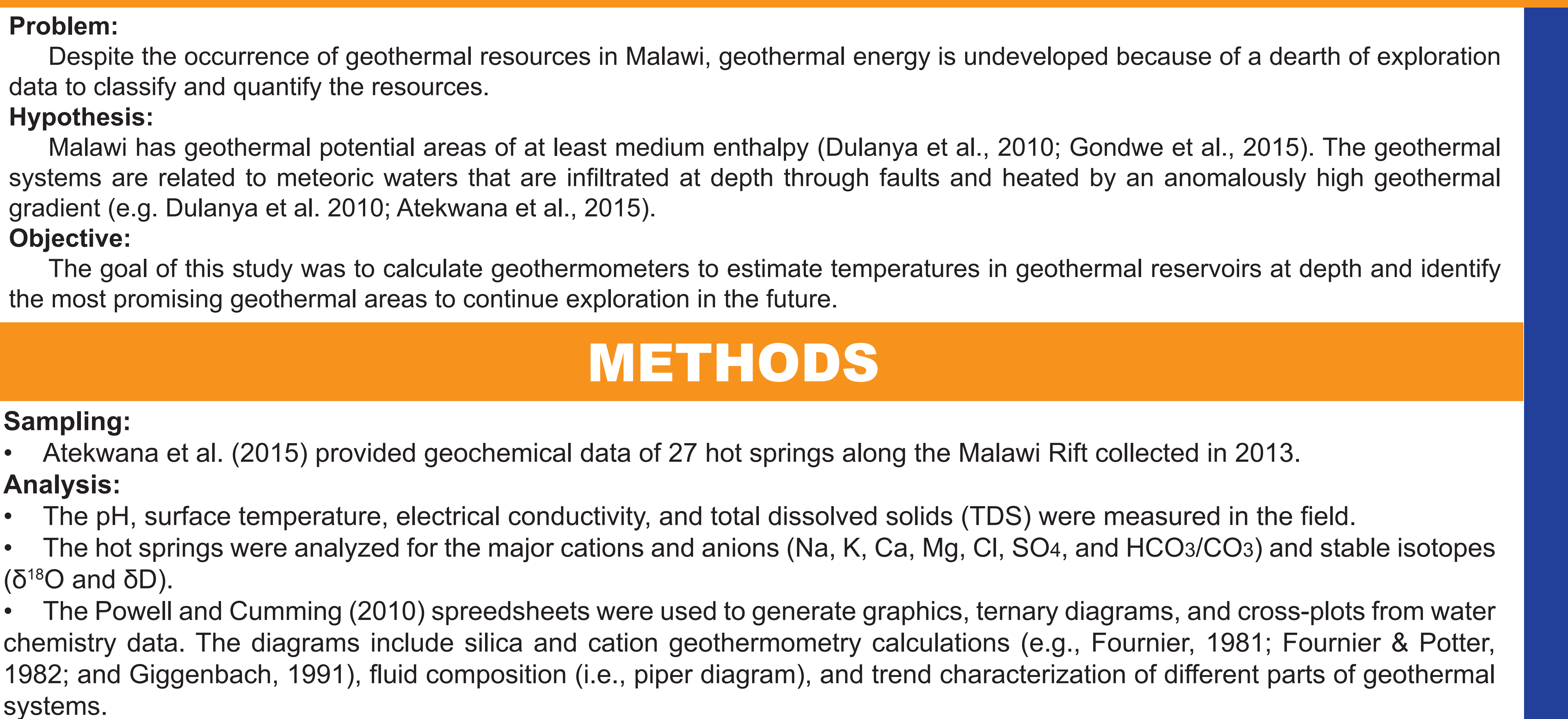

GEOCHEMISTRY OF GEOTHERMAL SYSTEMS
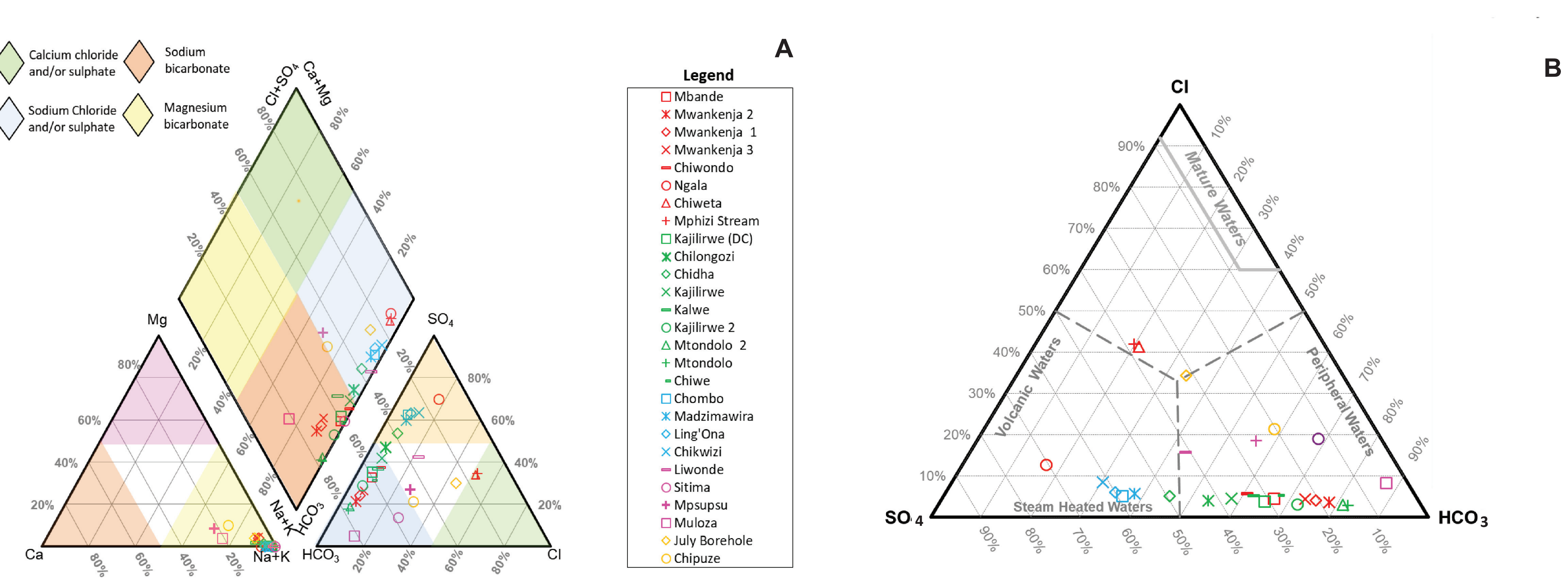

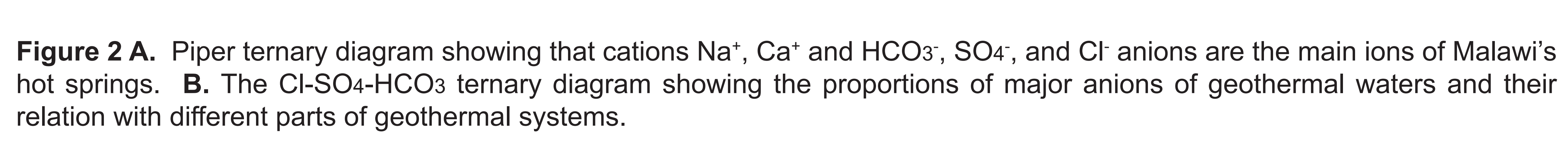

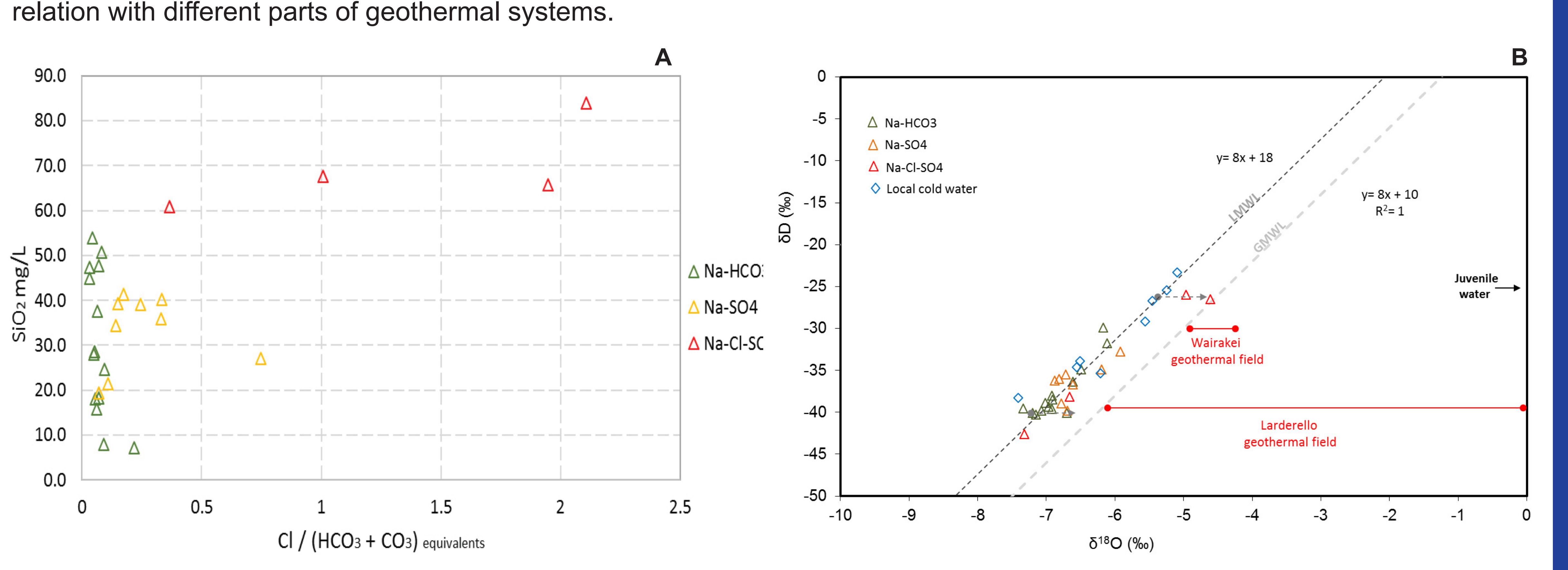

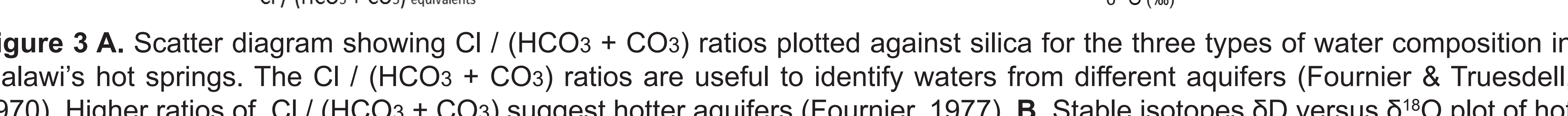

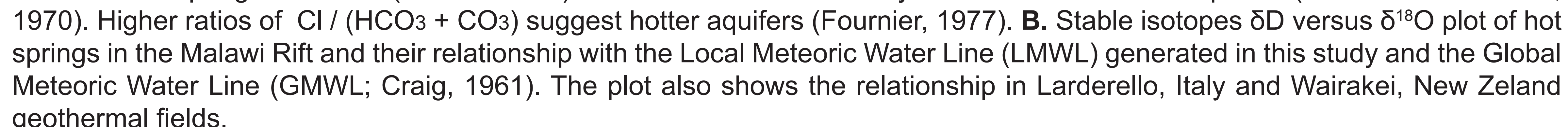

GEOTHERMOMETRY

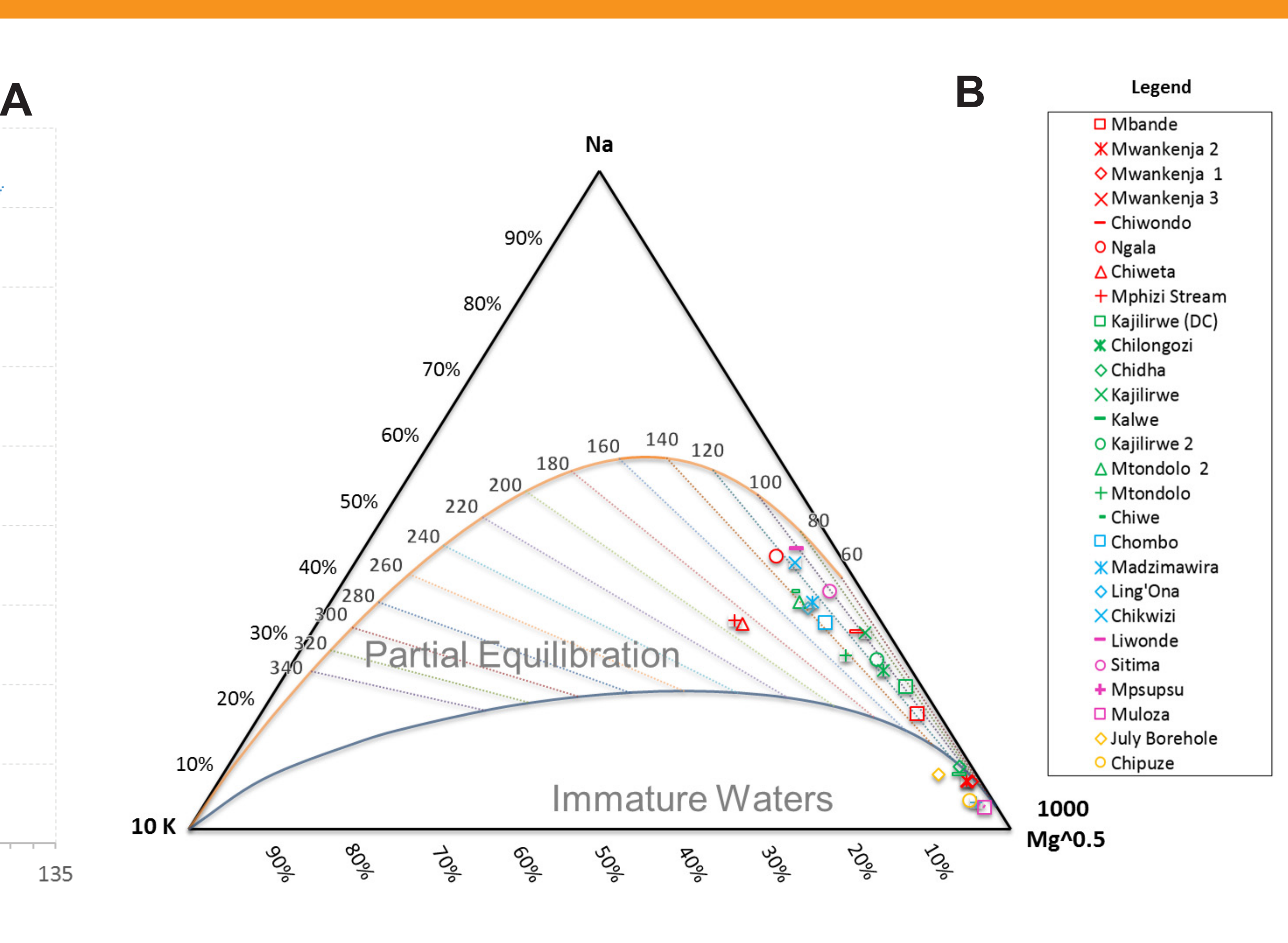

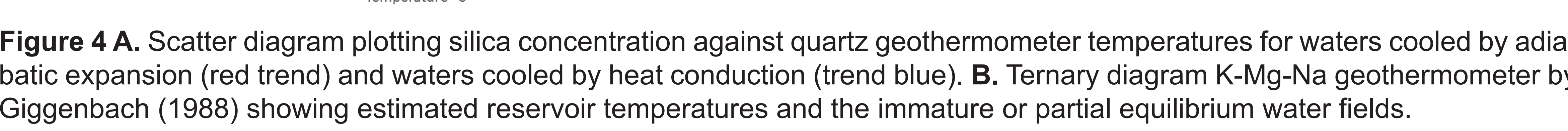

GEOINDIGATORS

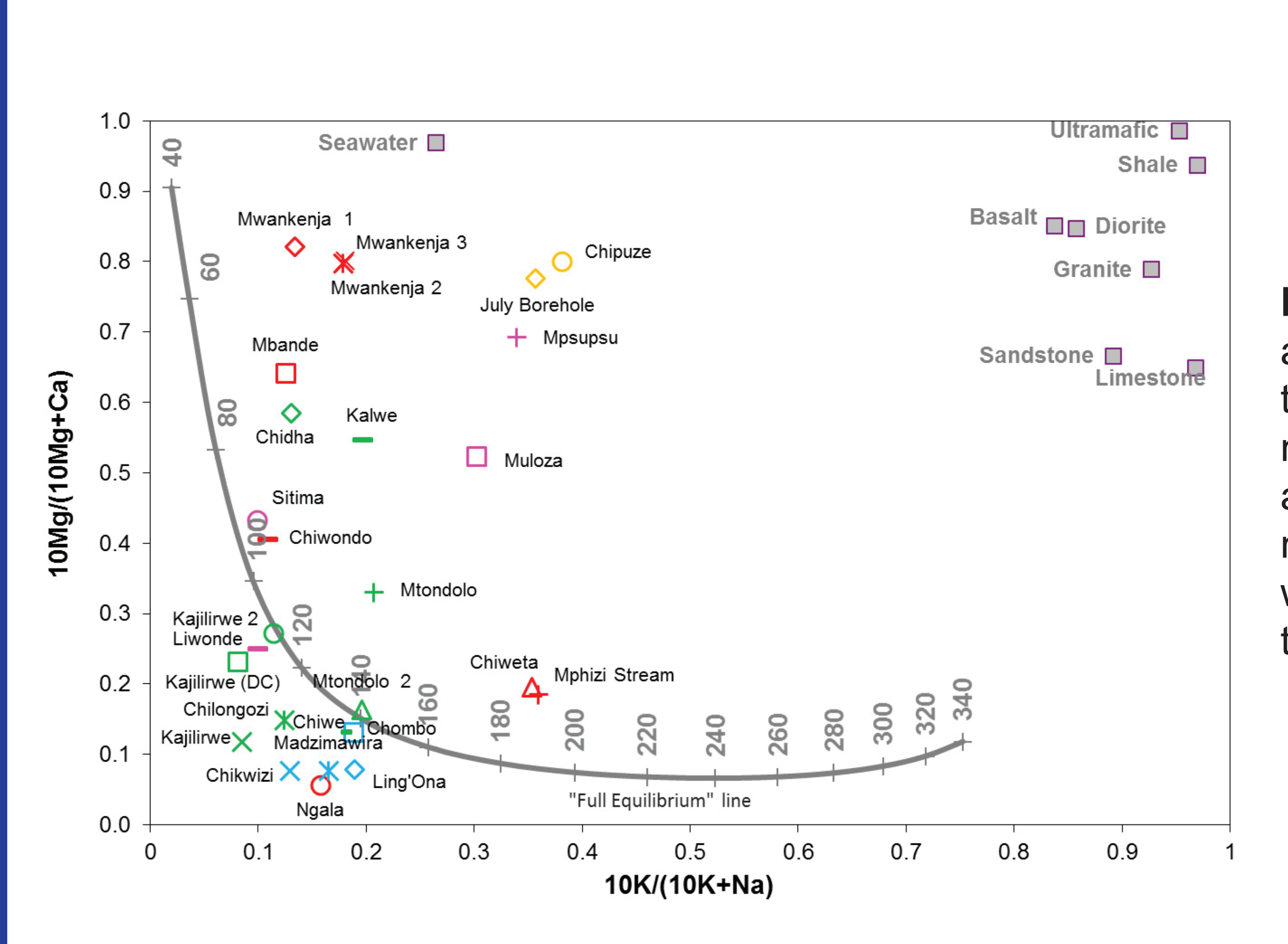

GEOTHERMAL CONGEPTUAL MODEL

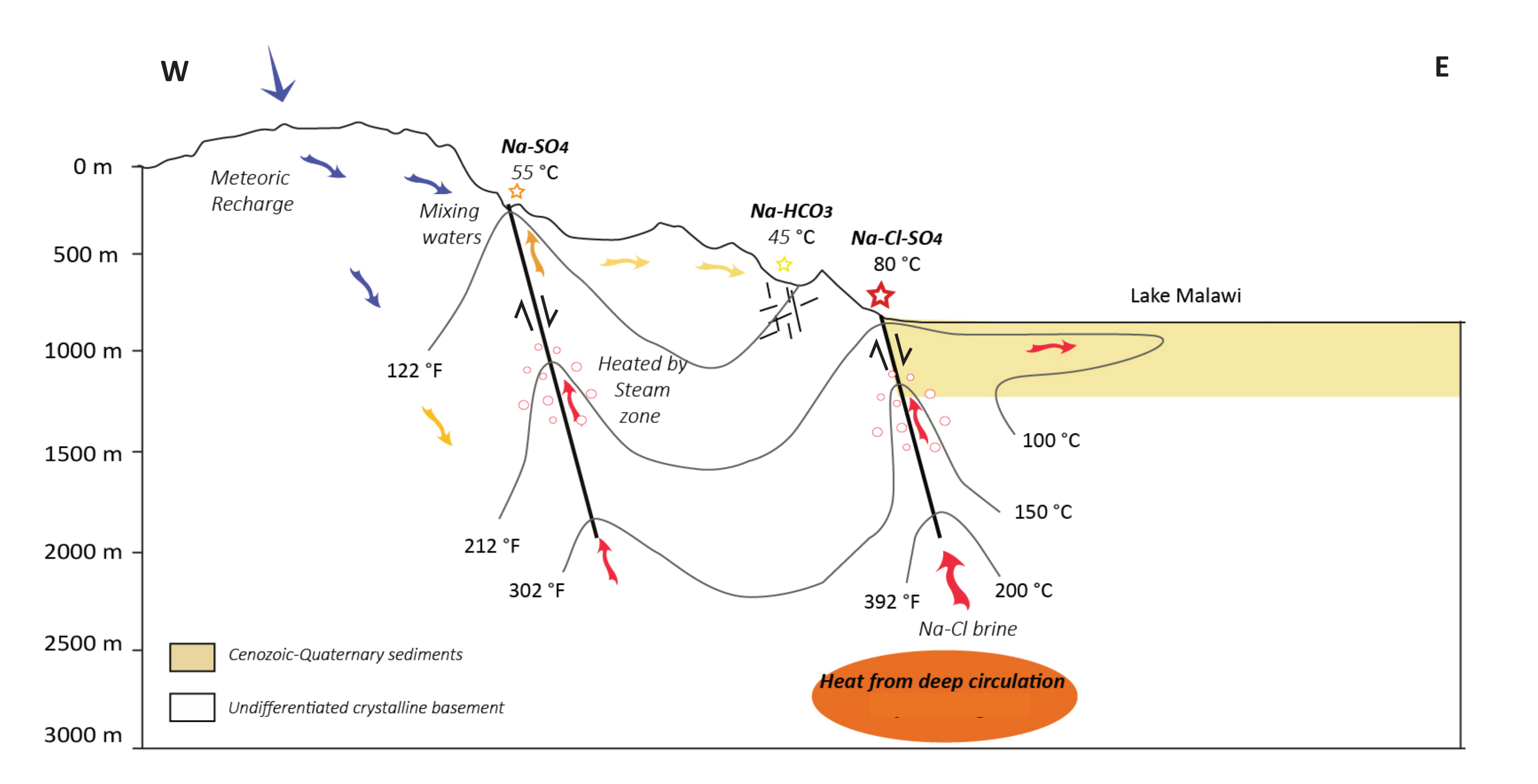

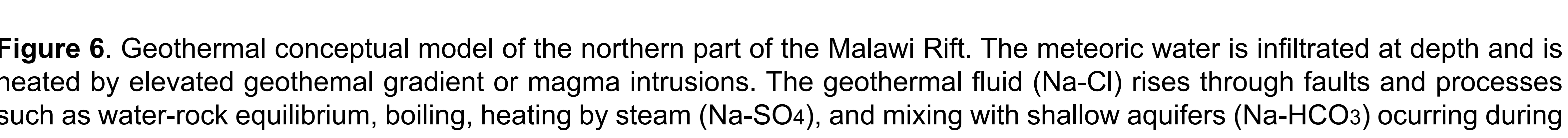

DISCUSSIONS

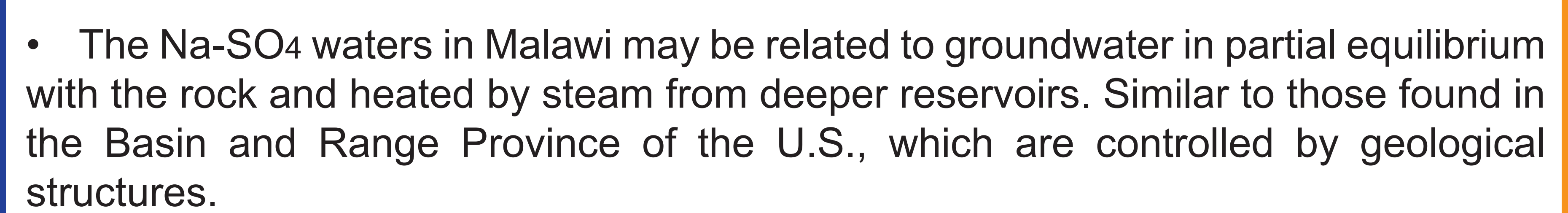

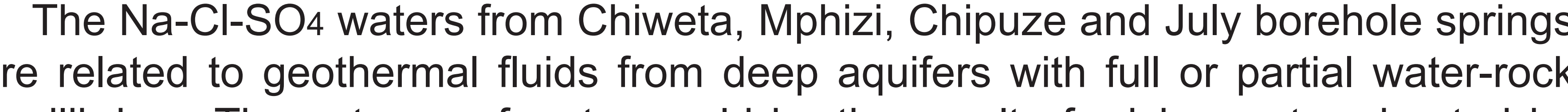
equilibrium. These types of water could be the result of mixing waters hersto
steam due to boliting and lor volcanic waters heated by intrusions at depth.

L The stable isotope of $\delta \mathrm{D}$ against $\overline{1}^{10} \mathrm{O}$ show that $93 \%$ of the hot springs lie on the . and they are in partial equilibrium with the rock. On the other $\mathrm{h}$ hed July borehole and Chipuze hot springs in southern Malawi also show reservair
temperatures around $190^{\circ} \mathrm{C}$. However, , July borehole and Chipuze hot springs have CONCLUSIONS

- The northern part of the Malawi Rift has the most prominent areas (Karonga) to - The results indicate that Chiweta hot springs area in Malawi have geothermal - The geothermal systems in Malawi are related to meteoric water infiltrated at depth
through highly permeable and deep faults. The meteoric water is heated by

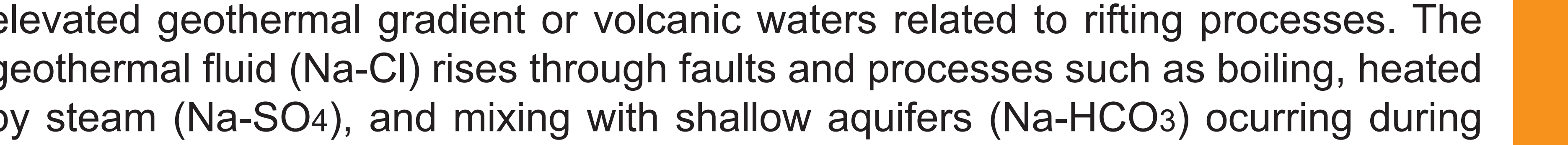
- Structural geology analysis should be conducted to better understand the hot fluid
storage, and pathways through faults in order to find the best exploratory wells ACKNOWLEDGMENTS

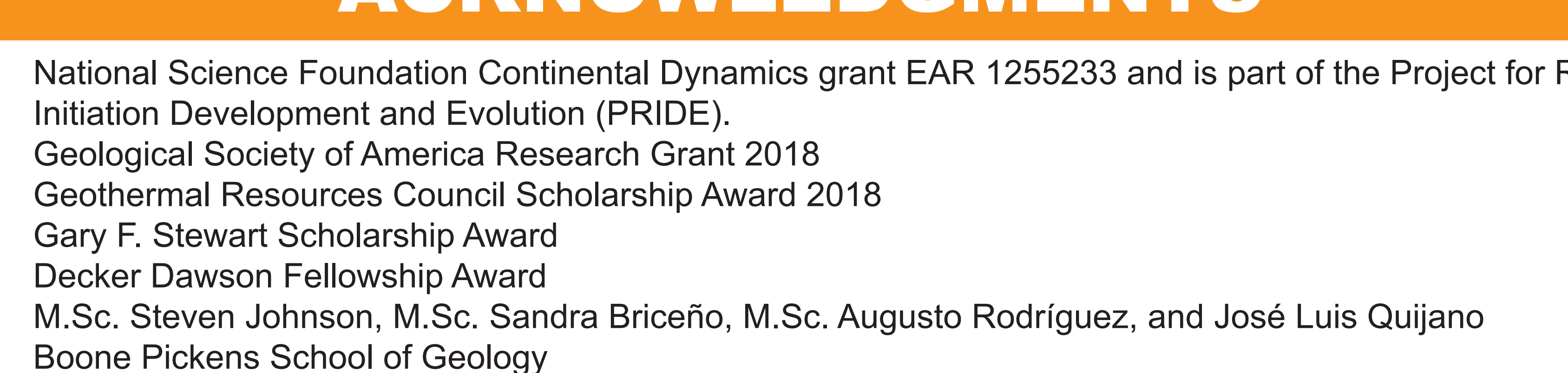

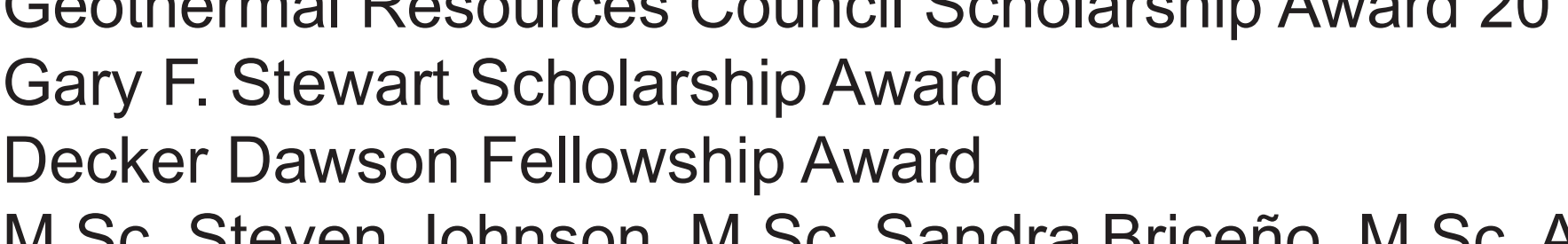

Jectonis Research Group okathoma State University
REFERENCES

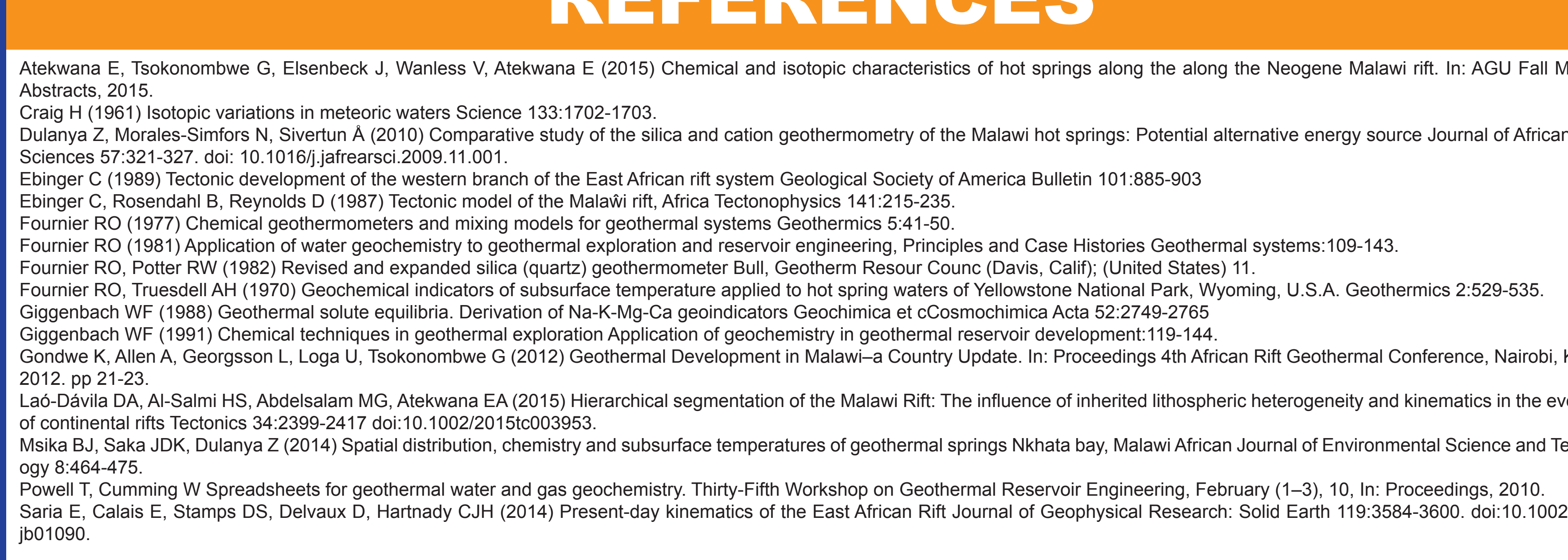

